\section{Commentary: Biomechanical differences after mitral valve repair: Is it time to use the science?}

\author{
Hani Ali-Ghosh, MBBS, FRCS (CTh), and \\ Clifford William Barlow, FRCS (CTh), DPhil
}

Mitral regurgitation is the most prevalent valvular disease in the developed world, with mitral repair being superior to replacement. ${ }^{1}$ Mitral valve repair was described more than 60 years ago, 2,3 and numerous repair techniques have since evolved. These can broadly be regarded as "resection" of leaflet, "respect" with neochords, or "edge-to-edge" leaflet repair. It is often the surgeon's subjectivity that steers their technique despite data existing regarding short- and longer-term efficacy and durability of these. ${ }^{4-6}$

In this edition of JTCVS Techniques, Paulsen and colleagues ${ }^{7}$ investigate biomechanical outcomes after mitral valve repair. Using their previously described model, ${ }^{8}$ porcine mitral valves were mounted within a 3dimensional-printed left heart simulator, P2 prolapse was induced, and hemodynamic data and chordal forces were analyzed after 4 different repair techniques-edge-toedge, resection, remodeling, and neochord. The authors find that edge-to-edge techniques are inferior in terms of regurgitant volume but importantly that the biomechanical properties of different repair techniques vary considerably. While both resection and nonresection techniques more effectively reduce regurgitation, the latter, such as leaflet remodeling or neochord, do so with lower chordal forces. The authors postulate that, with further studies, biomechanical data may direct choice of surgical repair strategy and lead to more durable repairs.

From the Department of Cardiothoracic Surgery, University Hospital Southampton, Southampton, United Kingdom.

Disclosures: The authors reported no conflicts of interest.

The Journal policy requires editors and reviewers to disclose conflicts of interest and to decline handling or reviewing manuscripts for which they may have a conflict of interest. The editors and reviewers of this article have no conflicts of interest.

Received for publication Oct 11, 2021; revisions received Oct 11, 2021; accepted for publication Oct 21, 2021; available ahead of print Oct 26, 2021.

Address for reprints: Clifford William Barlow, FRCS (CTh), DPhil, Department of Cardiothoracic Surgery, University Hospital Southampton, Tremona Rd, Southampton SO16 6YD, United Kingdom (E-mail: clifford.barlow@uhs.nhs.uk).

JTCVS Techniques 2021;10:252-3

2666-2507

Crown Copyright (C) 2021 Published by Elsevier Inc. on behalf of The American Association for Thoracic Surgery. This is an open access article under the CC BY-NCND license (http://creativecommons.org/licenses/by-nc-nd/4.0/).

https://doi.org/10.1016/j.xjtc.2021.10.042

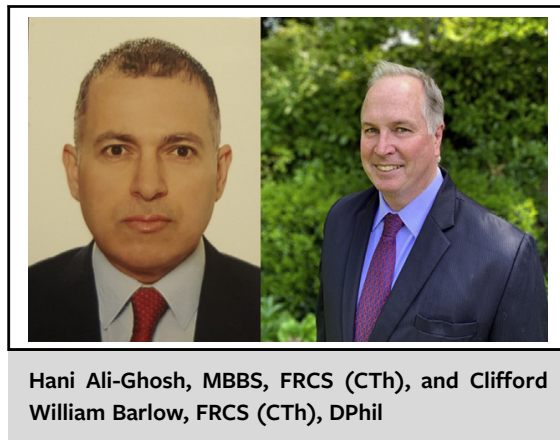

CENTRAL MESSAGE

Biomechanical chordal forces vary after different mitral valve repair techniques. These may influence durability and guide future repair strategy.

Limitations of the study fall into 2 categories. ${ }^{7}$ The first relate to the 3-dimensional-printed left heart simulator and its clinical transferability. These include the model ventricular size being larger than normal, use of mechanical valves in the aortic position, and chordal force measurement accuracy with differing degrees of regurgitation. However, as previously, ${ }^{8}$ the authors provide evidence that their model is reproducible for studying the biomechanics of mitral valve repair.

The second category of limitations relates to extrapolating biomechanical data after repair in their porcine model to pathologic human mitral valves. In their porcine model, chordal forces using nonresection techniques are being measured with normal leaflet tissue, and these may not extrapolate to an unresected, myxomatous, pathologic human valve. In contrast, chordal forces in their leaflet resection model are being measured after partial resection of a normal posterior leaflet. Perhaps this mimics the "overzealous resection" they correctly criticize in their introduction. $^{7}$ Finally, the most important difference between the study model and clinical practice is that annuloplasty rings, which restore annular shape and size but also possibly reduce chordal strain, were not employed as to not confound the results.

Surgical decision-making should be based on preoperative investigations and intraoperative assessment using sound surgical principles. The aim is a tension-free repair with a posteriorly situated, smooth line of coaptation. ${ }^{6}$ On occasion, all experienced mitral repair surgeons would 
resect some excessive leaflet tissue and on others would respect the entire leaflet. However, perhaps in a frail patient with mitral annular calcification, an edge-to-edge repair could deliver the optimal outcome. These decisions represent the art of surgery. While the experienced surgeon could often use several alternative techniques to repair a particular valve, comprehensive biomechanical data may provide an objective direction in the future for improved early- and longer-term outcomes. Surgeons need innovations, such as the research described by Paulson and colleagues, ${ }^{7}$ as we are ultimately scientists and not artists.

\section{References}

1. Gillinov AM, Blackstone EH, Nowicki ER, Slisatkorn W, Al-Dossari G, Johnston DR, et al. Valve repair versus valve replacement for degenerative mitral valve disease. J Thorac Cardiovasc Surg. 2008;135:885-93. 893.e1.

2. Lillehei CW, Gott VL, Dewall RA, Varco RL. Surgical correction of pure mitral insufficiency by annuloplasty under direct vision. J Lancet. 1957;77:446-9.
3. Carpentier A. La valvuloplastie reconstitutive. Une nouvelle technique de valvuloplastie mitrale. Presse Med. 1969;77:251-3 [in French].

4. Lapenna E, Del Forno B, Amore L, Ruggeri S, Iaci G, Schiavi D, et al. Durability at 19 years of quadrangular resection with annular plication for mitral regurgitation. Ann Thorac Surg. 2018;106:735-41.

5. De Bonis M, Lapenna E, Lorusso R, Buzzatti N, Gelsomino S, Taramasso M, et al. Very long-term results (up to 17 years) with the double-orifice mitral valve repair combined with ring annuloplasty for degenerative mitral regurgitation. J Thorac Cardiovasc Surg. 2012;144:1019-24.

6. Dreyfus GD, Dulguerov F, Marcacci C, Haley SR, Gkouma A, Dommerc C, et al. "Respect when you can, resect when you should": a realistic approach to posterior leaflet mitral valve repair. J Thorac Cardiovasc Surg. 2018;156: 1854-66.E3.

7. Paulsen MJ, Cuartas MM, Imbrie-Moore A, Wang H, Wilkerson R, Justin Farry J, et al. Biomechanical engineering comparison of four leaflet repair techniques for mitral regurgitation using a novel 3-dimensional-printed left heart simulator. $J$ Thorac Cardiovasc Surg Tech. 2021;10:244-51.

8. Paulsen MJ, Imbrie-Moore AM, Wang H, Bae JH, Hironaka CE, Farry JM, et al Mitral chordae tendineae force profile characterization using a posterior ventricular anchoring neochordal repair model for mitral regurgitation in a threedimensional-printed ex vivo left heart simulator. Eur J Cardiothorac Surg. 2020;57:535-44. 